\title{
A rare case of extraovarian primary peritoneal carcinoma in a 72 year-old woman
}

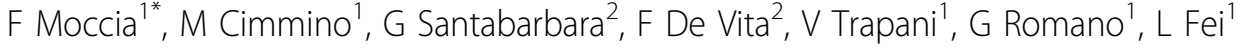 \\ From de Senectute: Age and Health Forum \\ Catanzaro, Italy. 5-7 December 2009
}

\section{Background}

Extraovarian Primary Peritoneal Carcinoma (EOPPC) was first described by Swerdlow in 1959 [1]. Basically, EOPPC is a malignancy that spreads widely inside the peritoneal cavity involving mostly the omentum with minimal or no ovarian involvement. Most of the EOPPC cases reported have been of serous histology; histopathological, immunohistochemical, and clinical similarities have been observed between EOPPC and Epithelial Ovarian Cancer (EOC).

\section{Materials and methods}

In June 2007 a 72 year-old woman was referred to our Unit for recurrent abdominal pain, constipation, loss of weight (BMI 17.5), serious asthenia and fever. Laboratory biochemistry showed hypocromic microcitic anemia, leucocytosis, increased plasma levels of flogistic markers and serious increase of CA 125 marker $(373,2$ $\mathrm{U} / \mathrm{ml}$ - normal range 0-35 U/ml). Abdominal US scan confirmed by CT scan (Figure 1), revealed a high vascularised solid mass close to the peritoneum (maximum diameter $10-12 \mathrm{~cm}$ ), ascites among intestinal handles and into Douglas pouch. The colonoscopy did not show any neoplasm. A solid mass not separable from omentum, irregular morphology was found by median laparotomy (Figure 2); no primary tumor was found anywhere else in the abdomen.

\section{Results}

The morphological features such as serous papillary carcinoma and the presence of many psammoma bodies and the immunohistochemical highly positive for CA 125 (Figure 3) have determined the diagnosis of EOPPC.

${ }^{1}$ Unit of General Surgery and Digestive Physiopathology, Department of Clinical and Experimental Medicine and Surgery "F. Magrassi-A. Lanzara", Second University of Naples, 80131 Naples, Italy
This patient received a first-line chemotherapeutic treatment with paclitaxel $\left(135 \mathrm{mg} / \mathrm{m}^{2} / 24 \mathrm{hr}\right)$ and cisplatin $\left(75 \mathrm{mg} / \mathrm{m}^{2}\right)$ in combination for six cycles. No evidence of recurrence was found at the 2-year follow-up.

\section{Conclusions}

As the EOPPC is mullerian malignancy as the epithelial layer of ovary and the peritoneum share a common embryological origin and it undergoes a chemotherapeutic treatment as ovarian primary carcinoma. Paclitaxel with platinum compounds have been introduced into chemotherapeutic regimens for EOC. In the first report describing the use of the combination of paclitaxel $\left(135 \mathrm{mg} / \mathrm{m}^{2}\right)$ and cisplatin $\left(50\right.$ to $\left.75 \mathrm{mg} / \mathrm{m}^{2}\right)$, given for six cycles in four EOPPC patients, Menzin et al [2] showed a complete surgical response in one patient and a partial surgical response in the others. Patients with EOPPC should be reported separately from those with ovarian carcinoma but should be treated in a similar fashion.

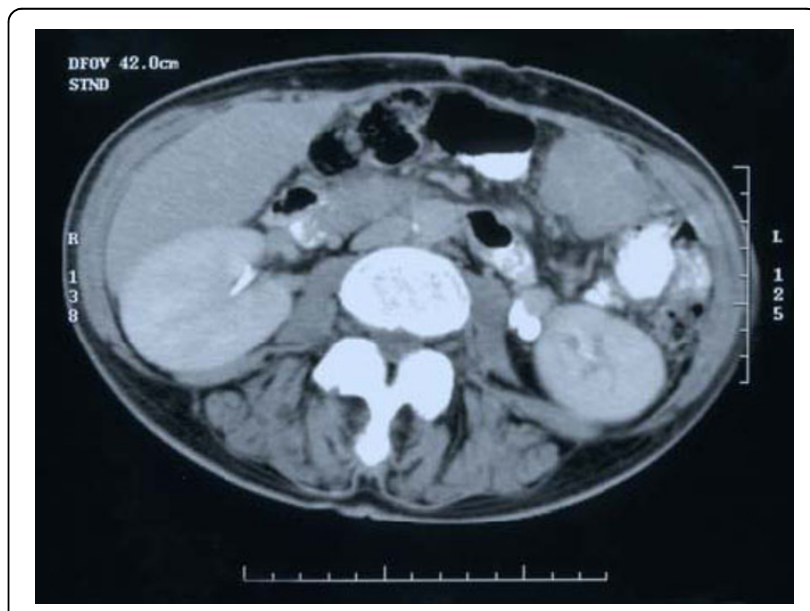

Figure 1 

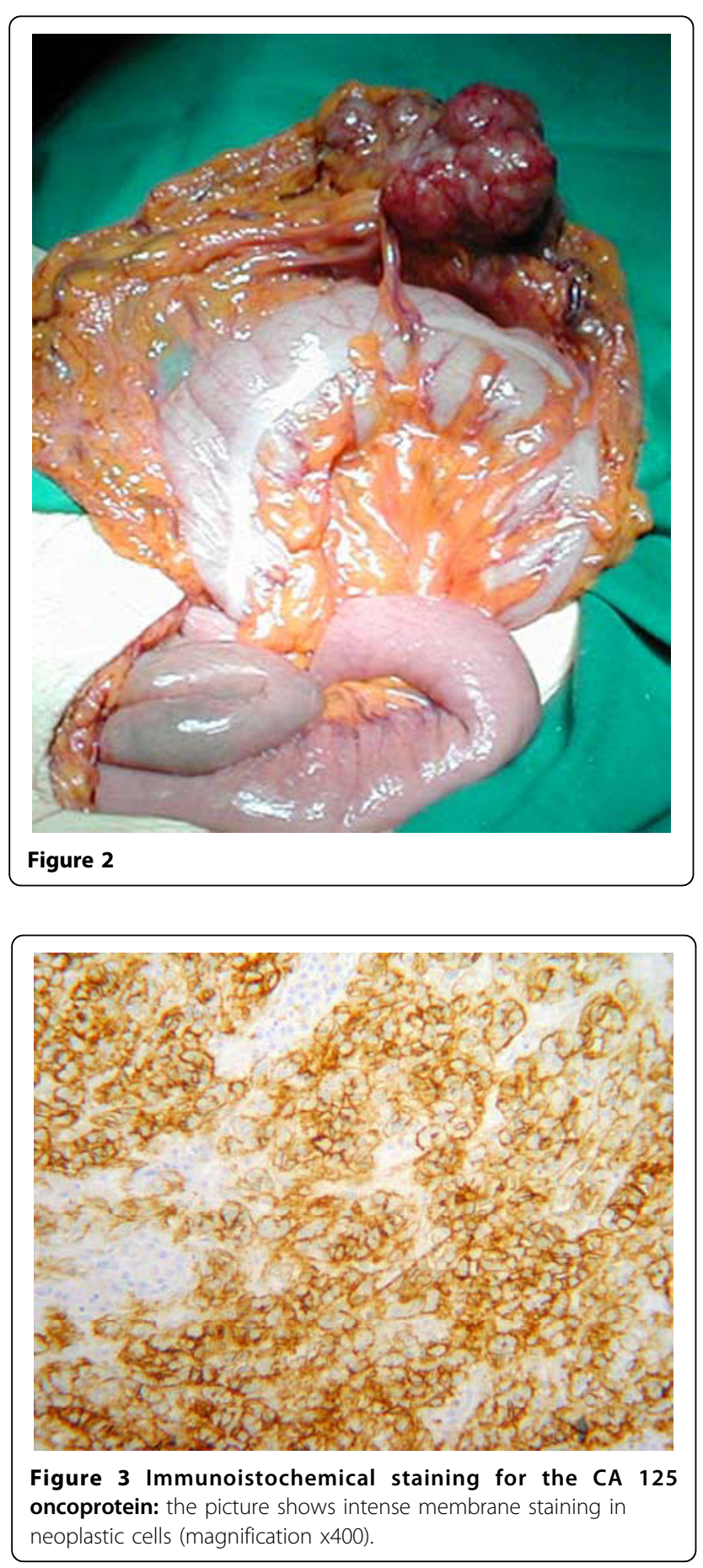

\section{Author details}

${ }^{1}$ Unit of General Surgery and Digestive Physiopathology, Department of Clinical and Experimental Medicine and Surgery "F. Magrassi-A. Lanzara", Second University of Naples, 80131 Naples, Italy. ${ }^{2}$ Unit of Medical Oncology, Department of Clinical and Experimental Medicine and Surgery "F. MagrassiA. Lanzara" Second University of Naples, 80131 Naples, Italy.

Published: 19 May 2010

\section{References}

1. Swerdlow M: Mesothelioma of the pelvic peritoneum resembling papillary cystadenocarcinoma of the ovary: case report. Am J Obstet Gynecol 1959, 77:197-200.

2. Menzin AW, Aikins JK, Wheeler JE, Rubin SC: Surgically documented responses to paclitaxel and cisplatin in patients with primary peritoneal carcinoma. Gynecol Oncol 1996, 62:55-58.

\section{doi:10.1186/1471-2318-10-S1-A16}

Cite this article as: Moccia et al:: A rare case of extraovarian primary peritoneal carcinoma in a 72 year-old woman. BMC Geriatrics 2010 10(Suppl 1):A16.

\section{Submit your next manuscript to BioMed Central and take full advantage of:}

- Convenient online submission

- Thorough peer review

- No space constraints or color figure charges

- Immediate publication on acceptance

- Inclusion in PubMed, CAS, Scopus and Google Scholar

- Research which is freely available for redistribution 